\title{
LA EXPEDICIÓN DE ALICANTE PARA LA TOMA DE ORAN (1732) Y SU SEGUIMIENTO EN TÚNEZ
}

Por

MÍKEL DE EPALZA

\begin{abstract}
En homenaje al historiador tunecino Slimane-Mústafa Zbiss, admirador de las tierras alicantinas de sus antepasados moriscos, con ocasión de su jubilación administrativa (1).
\end{abstract}

Es sobradamente conocida y está muy abundantemente documentada la expedición española de 1732 para la toma de Orán, objeto no hace aún tanto tiempo de la pluma lírica del historiador alicantino Francisco Figueras Pacheco (2). La abundancia de la documentación, sobre todo por parte española, se debe sobre todo al interés de la Corona Española por sacar partido político de la exitosa expedición ante las cortes europeas, como se puede ver en la distribución de lujosas reproducciones cartográficas del escenario bélico oranés por toda Europa (3). Fue un poco el "canto del cisne" de las conquistas españolas en la costa magrebí: el impresionante conjunto portuario de las ciudades de Orán y

(1) Slimane-Mústafa Zbiss nació el 4 de julio de 1918 en el pueblo de Testour, repoblado por moriscos expulsados de Espeña en el siglo XVli, sabre el río Medjerda, a unos ochenta kilómetros al aeste de Túnez. Arqueólogo e historiador, ha sido director general de Arqueologla y presidente de la Asociación para la Protección de la Medina de Túnez. Académico correspondiente de la Peal Acadernia de la Historia, de Madrid, y titular de diversas condecoraciones españolas y de otros países, fundó y dirigió hasta su jubilación el Centro de Estudios HispanoAndalusies, dentro del Instituto Nacional de Arqueología y Arte, máxima institución de investigación en estos campos, en Túnez. Entre sus publicaciones figuran diversos libros, artloulos y comunicaciones en congresos, de tema histófico: arte hispano-árabe en Túnez, epitafios de sabios de Al-Andalus en cementerios tunecinos, tradiciones tunecinas de origen morisco, itinerarios de los Banu Gániya mallorquines (siglos XII-XIII) en el Mágreb Driental, etcétera. Recientemente se ha publicado en Túnez - donde se le prepara un homenaje nacional- un libro colectivo, bajo su dirección: Etudes sur les Morisques Andelous (l. N. A. A. Túnez, 1983, $392 \mathrm{pp}$.l. En noviembre de 1981 dio dos conferencias en Alicante y Alcoy, visitó los poblamientos moriscos conservados en el norte de la provincia y descifró dos estelas árabes del Museo Arqueológico de Alcoy, en un artículo publicado en la revista de fiestas (vol. 1982, pp. 86-87): Las dos estelas arabes del museo de Alcoy.

(2) Santa Faz y Montemar (Evocación da la reconquista de Orán y sus castillos), Alicante, 1949.

(3) Ver M. de EPALZA, *Plarts et cartes hispaniques de I"Algérien, Archives Nationa/es, número especial 10-11, Actes du Séminaire International sur las Sources Espagnoles de /'Histaire Algárienne (Oran: 20-22 avril 1981), Afgel, 1984, pp. 55-69; M. de EPALZA y J. B. VILLAR, Plans at cartas hispaniques de I'Algerie (XVI"-XVII" sidcles), Argel, Bibliotheque Nationale, en prensa. Puede verse un ejemplo de esta iconografia «propagandísticaw en un óleo de Sani, «Embarco de las tropas del Conde de Montemar, en Alicantew, reproducido par F. G. SEl. JO ALONSO, Historia ilustrada del antiguo Reyno de Valencia, Alicante, 1984. En el campo de la literatura, además de la bibliografla recogida por C. RODRIGUEZ JOULIA SAINT-CYR, Bibliografla menor hispano-musulmana, Madrid, 1970, pp. 280-293, se puede ver el largo poema, de 40 páginas, editado en 1732 en BarceIona y Valencia y titulado *Resgo épico de la conquista de Orán, que a la diversión de los ofieiales de los regimientos de Guardias Españolas y VValonas dedica la ociosidad de un compañero suyow. 
Mazalquivir, que habian sido conquistadas por el impulso del Cardenal Cisneros en 1509 y 1504, respectivamente, y habían sido perdidas para España en 1708 , seria definitivamente entregado a Argelia en 1792 , tras un terrible terremoto en 1790 y los continuos ataques argelinos durante el año 1791 (4).

No se va a resumir aquí ni la historia de las relaciones entre Alicante $y$ Orán, aún por hacer (5), ni la de la expedición del conde de Montemar en 1732. Sólo se pretende aportar una documentación inédita y original : el eco que tuvo en Túnez, entre la población musulmana local y entre los extranjeros, esa expedición.

Se trataba pues de un uestudio de opinión pública» magrebí, en una sociedad donde la prensa escrita no había aparecido todavía y donde los documentos que podían reflejarla eran escasísimos (6). Esta opinión pública acerca de la expedición de Alicante de 1732 parece que sólo se ha estudiado de una forma completa en el caso de la prensa mexicana (7). El caso tunecino puede estudiarse gracias al "diario" de Francisco Ximénez, fundador y director del hospital de cristianos de Túnez por aquella época, documento excepcional y especie de estracto de los medios de difusión propios de la capital tunecina en aquel tiempo, es decir de las conversaciones de la capital.

Francisco Ximénez, religioso trinitario nacido en Esquivias (Toledo), se traslada en 1717 a Orán, por Alicante y Cartagena, para fundar allí un hospital. No logra su propósito y trabaja en el hospital de su orden en Argel hasta 1720 en que pasa a Túnez, para fundar allí el hospital para cristianos, que regentará hasta su vuelta a España, en 1735. Hombre erudito y curioso, nos ha dejado muchas obras de historia del Mágreb y de su orden religiosa, traducciones del árabe hechas con la ayuda de un tunecino descendiente de moriscos y sobre todo los densos volúmenes de su "diario", en los que va anotando todos los acontecimientos notables del día: en los 18 años de su estancia en el Mágreb. sólo he encontrado 23 días en los que pone la escueta frase "Hoy no he encontrado nada que reseñar" (8). El año 1732 tenía pues suficiente conocimiento de los asuntos magrebies - tras quince años de vivir en Orán, Argel y Túnezcomo para ser un buen testigo de la política hispano-musulmana en la zona.

Él mismo define su método en el prólogo del tomo segundo de su "diario",

(4) Las consideraciones económicas y militares del mantenimiento de asas plazas ruinosas pesaron mucho en el abandono final de Orán y Mazalquivir, como se desprende de los informes de los gobernadores, estudiados recientemente por M. EL KORSO y M. de EPALZA, Oran at /'Ouest algerien au $18 \mathrm{eme}$ siecle d'apres le rapport Aramburu, Argel, 1978. Es conocida la frase de un gobernador español de Orán que decía que allí se empleaba más esfuerzo en luchar contra el hambre que contra el enemigo.

(5) Dos recientes trabajos abren un camino prometedor en este tema: E. GIMENEZ, «Fuentes para el estudio de las

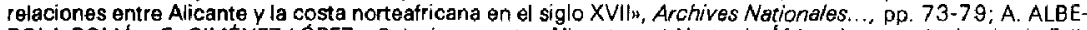
ROLA ROMA y E. GIMENEZ LÓPEZ, "Relaciones entre Alicante $\gamma$ el Norte de Africa durante el reinado de Felipe $V_{*}$ (en prensa)

(6) En Argelia se están publicando actualmente fuentes literarias en árabe (poemas populares, crónicas locales memorias de personáes, etc.) que se hacen eco de estos hechos. Ver M. de EPALZA, M. BENALI Y A. GAFSI, "Producción tunecina y argelina sobre historia de España desde la independencia 11956 y 1962 /" Indice Histórico Espeñol, Barcelona, vol. XV, n. ${ }^{\circ} 56$ bis, $1969 / 1975$, pp. XI-LXI1; M. de EPALZA, Ecrits relatifs à /'histoire de l'Espagne publiés en Algérie de 1962 1973, Argel, 1976.

17) Ver R. RICARD, "L'Afrique du Nord dans la "Gaceta de México", 1728-1742", Hespéris, Rabat, XV, 1932. 53-78.

(8) Presentación del autor y de su obra conocida en M. de EPALZA, "Nuevos documentos sobre descendientes de moriscos en Túnez en el siglo XVHlln, Studia historica et philologica in honorem M. Batllori, Roma, 1984, 196 228; M. de EPALZA Y H. AL-USLATI, "Mulăhazât ab isbânî yazûru Wahrân fî ahd Mustałà Búshlâgamn lObservaciones de un eclesiástico español que visita Orán en tiempos de Mústafa Bushlágaml. Revue d’Histoire Maghrebine, Túnez, 12, 1978, 191-201 
titulado Viaje a Arge/ (9): "No es obra ésta en que necessité de valerme de autores que la corroboren, porque sólo trata de cosas que pasan cada día, unas que pasan por mis ojos, y otras que me refieren los cautivos, y como es, assílo refiero, para si acasso los que lo leyeren, quisieren valerse de alguna cosa, para alguna historia..."

Sin entrar en detalles, sus afirmaciones coinciden con las de dos viajeros que se sirvieron de él en sus asuntos tunecinos: el redentor de cautivos español Melchor Garcia Navarro (10) y el diplomático y geógrafo francés Peyssonnel (11). El primero coincide además con Ximénez en su interés por los cautivos españoles de la toma de Orán por los argelinos, en 1708.

En efecto, la caída de Orán y de toda su guarnición habia sido una catástrofe para España. Miles de soldados y civiles, de todas las clases sociales, al no rendirse sino por la fuerza a los asediantes, fueron hechos prisioneros y desperdigados por toda la costa del Mágreb, en situaciones varias pero generalmente lamentablés. Esta situación había sido el motivo principal del envio de Francisco Ximénez a fundar un hospital en Orán, proyecto que se frustró por el justificado temor del bey de Orán de que los españoles actuaran de informadores del ejército español, en una futura expedición para reocupar la plaza.

En el "diario", los antiguos oraneses españoles aparecen continuamente. En una lista que le envían de Orán (26-11-1720) anota: "... los cautivos... de la rendición de Orán, sesenta y nueve... se han rescatado de la pérdida de dicha plaza, veinte y cuatro... los que han muerto de Orán... de los soldados, veinte y seis... an renegado de los soldados, doze... los que se an huido sin averse savido jamás de ellos, y se presume los aya muerto los moros o se los ayan comido las fieras, cuatron. Cautivos en espera de rescate o convertidos al Islam para insertarse en la sociedad magrebi, ésos son los españoles de Orán que conocerá Francisco Ximénez, entre 1720 y 1730 , en Túnez. Cada breve mención esboza un perfil de vidas individuales lanzadas en la sociedad magrebí, pero también nos indican cómo azuzaban el interés del padre Francisco Ximénez por todos los asuntos referentes a Orán.

\section{La espectativa de la expedición}

La primera mención de la futura expedición aparece en el "diario" el 29 de mavo: el Consejo de Guerra tunecino sabe que los argelinos están desplazando sus cuerpos de ejército turco de la parte meridional y oriental del país hacia Argel y Orán, en la costa septentrional, "con la noticia que tienen del gran armamento que se hace en España, que se cree que sea para una de estas dos ciudades». Unos días más tarde (el 1 de junio), repite la información militar y añade: "Se dice que en Argel an hecho salir fuera de la ciudad las mujeres, niños $y$ todas las personas incapaces de tomar las armas...". El 3 de junio, se hace eco

(9) Para no cargar inútilmente este artículo con notas, no se mencionará el folia del volumen en que aparecen las cá tas, sino las fechas del diario, rigurosamente correlativas. Esta cita está tomada del prólogo del t. 2. ${ }^{\circ}$, correspondiente al 1 de junio de 1719 .

(10) M. VÁZQUEZ PAJARO, Melchor Garcla Navarro. Redenciones de cautivos en Africa (1723-1725), Madrid, 1946. En la p. 325, hace referencia a cautivos de Orán instalados en Túnez.

(11) J. A. PEYSONNEL, Relation d'un voyage sur les côtes de Barbarie fait par ordre du Roi en 1724 et 1725 , París, 1885 ; PEYSONNEL a DESFNTAINES, Voyages dans les régences de Tunis et d'Alger, París, 1938 , donde el primero escribe del P. Francisco Ximénez: "Ce père est fort curieux et il m'a accompagné dans la plupart de mes voyages: (p. 167 ). 
de otro rumor: "... Algunos dicen que la armada de España ya avía arribado a Orán, y que iban cerca de seiscientas velas entre vageles de guerra y de transportes". Por estos testimonios anónimos - «la noticia que tienen", "se dice", "algunos dicenn - se ve el sentido que tiene Ximénez de la opinión pública del ambiente en el que se mueve, como se verá también en los meses que seguirán.

El 5 de junio escribe: "Los Moros tienen miedo al grande armamento que se hace en España, temiendo sea para la Berbería». El temor de los argelinos pasa ahora ya a los tunecinos: "El Bey ha embiado a los castillos del Reyno pólvora y balas para ponerlos en estado de defensa en casso que los Españoles quieran accometer este Reynon. Los españoles de Argel informan también a Ximénez: "A venido una embarcación en que hemos recibido cartas de Argel, $y$ nos dicen los miedos conque están los Argelinos de que la Armada de España vaya allá y que aquel Dei avía mandado poner en estado de defensa los castillos, y los judíos sacaban la ropa a los jardines [se refiere a los muebles, a las casas de campo de la parte alta de las colinas de Argel, al sureste de la ciudad], yno dexaban en las cassas ni aun un clavo».

El hospital español de Túnez tiene que sufrir, evidentemente, algunas consecuencias molestas de este estado de ánimo general: "Oy a las dos de la tarde [el 24 de junio] vino al hospital el Guardián Baxi Alí, alias Fernando Muñoz de la Pressa, natural de Barcina, y el Lamín de las obras, de orden del Bey, a registrar la cisterna, que no tiene agua, sospechando no hiciéssemos en ella minas o tubiéssemos oculta pólvora o municiones de guerra, como somos Españoles y el armamento que saben hace España, y por aver corrido en otra ocassión la voz que hacíamos minas, y teníamos barriles de pólvora y balas".

El 1 de junio las noticias se precipitan: "Ha venido una embarcación de la christiandad y a dicho que la armada Española está en La Furmentera lla isla de Formentera], y se crehe que vaya a Argel». La compleja política entre las dos "regencias" turcas de Argel y de Túnez aparece muy clara en el acertado análisis de Ximénez: "El Bey a hecho tener Diván de los turcos sobre la armada Española, que se dice sea destinada para la Berbería, y porque, según se dice, el Dey de Argel a embiado a pedir gente a este Reyno. El Bey, por una especie de política, mostraba en el exterior querer ir a socorrer a Argel, pero como los presume enemigos [a los argelinos], y que, si no dessea que los Cristianos se lleben a Argel, al menos quiere que los aprieten, por quanto le están haciendo [los argelinos] pagar cada año gruessas cantidades, porque le tengan en seguridad a Ali Baxa [su sobrino y pretendiente al gobierno tunecino]: por esso hizo que el Dauletri de Túnez juntasse el Diván y por instrucción del Bey dio al Dauletri el parecer que no era conveniente enviar socorro, porque los Españoles que ahora no se guardaban de venir contra este Reyno, si sabían que los tunecinos iban a socorrer, vendrían contra él, por lo qual le parecía no era conveniente embiar a ninguno a Argel. Y todos los demás del Diván le siguieron en este parecern.

La información política de Francisco Ximénez es igualmente certera por parte europea: "Escriven de España que el armamento que se hace en aquellas costas es para tomar Argel y Orán, y dársela a los ingleses en cambio de Puerto Mahón y Gibraltarn (nota del 12 de julio).

Noticias de fuente diversa anuncian que la armada está frente a Argel: el 19 de julio, es un corso que viene de Constantina; el 21, una embarcación de Cerdeña, donde los españoles cargaban trigo para la expedición. El 25 , la in- 
formación está en la corte de Túnez: "Se dize que ahier vino una carta de Bona a este govierno en que se refiere cómo la armada de España a desembarcado en Orán y los vageles de guerra an ido a bombardear al mismo tiempo a Argel. Se quentan otras muchas cosas que no escrivo por no tenerse en cuentan. Se ve que el propio Ximénez no sólo reproduce rumores, sino que valora las informaciones.

La noticia del peligro para la costa magrebi ha llegado hasta Oriente y provocado el reclutamiento de musulmanes para ayudar a sus correligionarios del Mágreb: "A venido una embarcación francesa de Levante que trahe 60 turcos de reclutas para Argel. Y no se sabe si irán desde aquí por tierra o por mar, porque quieren que, si van por mar, les asegure el cónsul francés" (nota del 26 de juliol.

Era demasiado tarde. Orán habia caido ya en manos del ejército español. El día siguiente, 27 de julio de 1732, llegaba la noticia a Túnez: "Se ha tenido noticia de aver los Españoles tomado a Orán, como lo dice la copia de esta carta que escriven al Cónsul francés".

\section{La toma de Orán y sus consecuencias}

He aqui el texto que debió causar conmoción en Túnez, especialmente en la numerosa colonia extranjera de cautivos, comerciantes y diplomáticos: "Extracto de una letra de Monsieur Fenix en La Cala [factoría pesquera francesa en teríitorio argelino, junto a la frontera tunecina, donde los genoveses dependientes de España tenían la factoría de Tabarka], en 20 de julio de 1732 .

"Yo expido este correo para decir a $\mathrm{Vm}$., que yo vengo de recibir tan solamente un correo de Bonna por el qual Monsieur Cauvin me dice que el patrón Donaud arribó aquí viniendo de Argel, de donde falta ya a nueve días, el qual a trahido la noticia de la pressa de Orán el primer día de este mes. An asegurado que los Moros de aquél país se hecharon cassi todos de la parte de los Españoles contra los turcos, lo que aviendo visto el Bey de dicho Orán, se huió con tres de sus mugeres. Le han dado la falta de esta pérdida, por haverse mucho fiado de los Moros, los quales unidos a los Españoles an saqueado a Orán."

La noticia de una primera reacción argelina llega al día siguiente: unos pesqueros de coral de Tabarca son apresados. "Debe de ser en despique [galicismo: despecho] de saber que aquella Isla pertenece a España».

El día 29 las noticias ya fluyen a Túnez de todas partes: «El Cónsul Imperial [de Austria] a tenido carta del Campo del Bey en que le dicen que la armada de España a tomado a Orán y que se encamina a Argel. Otra embarcación inglesa dicen que arribó de La Goleta viniendo de Gibraltar y confírmasse la noticia de la pressa de Orán por los Españoles y que solamente avían muerto ocho granaderos en la toma de aquella plaza. También se dice que los Argelinos an tomado una embarcación inglesa y pareze quieren hacer la guerra contra todos los Cristianos, porque eran embarcaciones de todas naciones a llevar víveres en la armada de España».

Pero hay un control tunecino de las noticias: el 30 de julio "a un moro que traxo de Cabo Bueno la noticia de Túnez de la pressa de Orán, le an puesto presso y le hubieran dado de palos y tal vez muerto si el Chiaya Achi Solimán no lo hubiera impedido hasta saber si era verdad o no lo que decia; se a confirma- 
do por diversas partes la pressa de Orán, y con esso se a librado de los palos, mas le tienen aún en prissión; le acussaron que avía levantado de su cabeza esta notizia para que los Christianos le diessen dinero". "Un cautivo sardo a quien su Patrón maltrataba y le daba de palos, le dixo: "Maltrátame que ya vendrán los Españoles y te quitarán los cuernos". Por lo qual le puso en cadena en el baño de Sta. Cruz y después le vendió a otro Patrón, y no le quiso tener consigo". "A otro christiano cautivo que hablaba sobre esta guerra en fabor de los Christianos le dieron de palos, por lo qual es necessario callar delante de ellos, y dexarles decir lo que quieran, publicando cada día que an derrotado totalmente la armada christiana."

El día 31 ya llegan noticias más detalladas, de la prensa europea, donde se ve todo el alarde informativo de los españoles alrededor de la expedición:

"A venido embarcación francesa de Liorna y el capitán refiere que los Españoles tenían sitiado a Orán y ya se avian tomado tres fortalezas. Las gazetas avisan las grandes precauciones que se hazían para este armamento, que 150 embarcaciones eran empleadas sólo para llevar heno, paja y agua. Que las tropas destinadas para Orán arribaron a 35 mil hombres y se embarcaron 20 mil fusiles y 14 mil pares de pistolas, sin otras armas de quienes dichas tropas serán abundantemente provistas. Y que se hacian en Barcelona dos puentes volantes para desembarcar más cómodamente la cavallería."

"El Conde de Montemar va comandante de esta grande armada, en que van más de 600 embarcaciones de transporte. Se crehe que este armamento principie por Orán, para ir después a Argel. Lleban en la armada quantidad de sillas por la cavallería, 18 hornos de campaña para cocer el pan, 29 mil palas y azadones, 60 mil faginas [!] largas de 18 pies, 81 mil sacos de lana, 17.220 saburies [!], 80 mil fuegos artificiales de mano, 125 mil libras de pólvora, 21 millones de raciones de pan, 24 mil messuras de agua, 80 mil arrobas de paxa."

Bajo la apariencia objetiva y voluntariamente aséptica de las noticias de Francisco Ximénez no se puede esconder el optimismo de las esperanzas que el éxito de la expedición de Orán despertaba entre los cristianos de Túnez: "Por una embarcación francesa - escribe Ximénez, el 1 de agosto - ... se ha sabido que los Españoles tomaron Orán en tres días y que iban a tomar Argel".

Dos días después (3-VIII-1732), se hace eco por el contrario de las reacciones tunecinas, gubernamentales $y$ populares, con hechos muy concretos: «Se a dicho que los Españoles tienen sitiado por mar y tierra a Argel, mas no quieren que se diga. Los Moros an embiado un recado a Monsieur Villet [el cónsul francés en Túnez] para que no publique la pérdida que han hecho los Turcos de Orán. ... V los Morillos muchachos jugando se vendían unos a otros como esclavos, de lo que an querido tomar presagio algunos de la felicidad de las armas españolas contra los Turcos". Esto no impide, según el "diario" de esos días, que el director del hospital español trata normalmente con las autoridades tunecinas de diversos problemas de cristianos cautivos.

Por una carta que recibe Ximénez, el 6 de agosto, de su colega el director del hospital español de Argel, se ve que Túnez constituye, para cristianos y musulmanes, una retaguardia más segura que Argel contra los ataques españoles.

"A venido una embarcación de Argel y he tenido carta del Pe. fr. Francisco 
Navarro, en que me dice que envía por vía de Buena [Bona, Hipona, ahora Annaba, en Argelia] doscientas y dos monedas portuguesas, para en casso que suceda algún contratiempo en aquel hospital, se pueda aprobechar éste, mas que hasta ahora los Turcos no les havian hecho molestia alguna. Y se a confirmado la toma de Orán por los Españoles, con pérdida sólo de diez hombres y pocos heridos. $Y$ de los moros no se sabe los que murieron. Desembarcaron el día 19 de julio. Huyeron los turcos y moros de la plaza y de los castillos con el Bey, y en Almarza [Mazarquivir] quedaron 90 turcos, que se entregaron a discreción. Salieron por entre las tropas con el turbante debaxo del brazo, que para ellos es de la maior afrenta, y cruzados de brazos. Y los embiaron con esta embarcación a Argel. Trahe [la embarcación que trae la noticia a Túnez] tres Embiados con tres caxas de dinero, dos para aqui, que vienen a pedir socorro, y una para el gran Señor [de Istanbul], para que les socorra."

El propio padre Francisco Ximénez acusa físicamente la tensión vivida en Túnez con esos acontecimientos. El 7 de agosto tiene «una cólica con grandes angustias que me hallé con bastante trabaxon. Se había pasado todo el día intentando esconder a un aventurero español, llegado de Marruecos y con visos de hacerse musulmán para que le dieran "la paga y sueldo de coronel» y llamado Antonio Espinosa de los Monteros, conde de Espinosa y caballero del hábito de Santiago. "Yo le dixe que aquí corría grande riesgo su vida, porque en las circunstancias presentes de hallarse la armada de España en Berbería, sospecharían que era espia, y se ponía él en peligro de que le ahorcassen y nos ponía a todos. $Y$ assí que tratasse de poner su persona en seguridad, y para esso le hize quitar la espada, que traía ceñida, y el plumaje del sombrero, y que no saliesse fuera... Mas el P. fr. Juan fue a estar con el Cónsul francés para ver cómo le podia hazer a este hombre embarcarn. Acaba renegando del cristianismo y convirtiéndose al Islam "creyendo que aquí tendrá muchas conveniencias", escribe Ximénez, unos días después (13-VIII-1732).

La conciencia del peligro de un ataque español a otros puertos magrebies es cada vez mayor. El 11 de agosto "se dice que la embarcación que a venido de Argel a trahido grandes cantidades de dinero que aquel Governador o Dei embía aquí en depósito a este Diván. Al capitán le engañaron y le dieron unas botas dándole a entender que era de piedra alumbre, pero realmente son de dinero y halajas de plata y oro, y por encima está la piedra alumbre, para que no lo supiesse ninguno y para que no lo llegasse a entender el pueblo. Y espera salvarlo, no lo tomen los españoles si fuessen a la conquista de Argel». El 14 "vino el Guardián Bassi y nos dio la noticia que avía venido un sendal de Buena, ciudad del Reyno de Argel, y los moros que venían en él avían dado noticia que estaba sitiada Argeln.

A pesar del secreto que procuraban las autoridades, el pueblo de Túnez estaba perfectamente al corriente del desastre musulmán de Orán. Lo expresan, como hemos visto ya, los chiquillos por la calle: "Un muchacho morillo, movido de sí mismo, iba diciendo por las calles más públicas que se saliessen los Moros de la ciudad, porque venían los Christianos, que eran los dueños de esta tierra. Los moros, que oyeron esto, le prendieron y llevaron al Bey, quien le mandó dar de palos, para que confessasse quíen se lo avía mandado decir, sino que aquello lo avía venido a la cabeza. Y teniéndole por loco, le llevaron al hospital de los que les falta el juicion.

Del 22 al 24 llegan diversas noticias sobre amenazas $v$ toma de Argel o de 
retirada de la armada española hacia España. Ximénez tiene que añadir al margen, seguramente unos días después, "A sido mentira".

El 15 de septiembre, más de dos meses después de la toma de Orán, el director del hospital de Argel informa a su colega de Túnez "cómo no les an hecho mal alguno". No hubo represalias contra el hospital español de Argel, lo cual no sólo demuestra respeto y tolerancia hacia quienes no tenían ninguna responsabilidad en las decisiones de su gobierno contra Argelia, sino también continuidad en la política de los gobiernos musulmanes en el tema de los hospitales: era la manera de mantener la salud y por tanto el valor productivo de los esclavos cristianos.

Epilogo del verano de la expedición de Alicante contra Orán es la muerte del gobernante supremo argelino. EJ 18 de septiembre escribe Francisco Ximénez: "Dícesse que a muerto el Dei de Argel y que a entrado en su lugar el Jaznadar [cargo equivalente a ministro del Tesoro]. Se crehe que a sido de la pena $y$ sobresalto que a tenido de la presa de Orán por los Españoles y sustos que tenía no fuessen sobre Argeln.

El «diarion de Ximénez seguirá contando acontecimientos relacionados con Orán: batallas y escaramuzas alrededor de la plaza, prisioneros por ambas partes, rumores de una nueva expedición española en el Mágreb, etcétera. Pero todas estas informaciones desbordan el marco del tema de este artículohomenaje.

Es evidente que el tema y la época remontan a una época en que las relaciones hispano-magrebíes eran mucho más agresivas que las actuales. El cambio se ha hecho - durante dos siglos y medio - con muchos factores sociales. Pero uno de ellos ha sido ciertamente con acciones pacíficas de investigación histórica y de cultura, como las del señor Slimane-Müstafa Zbiss. 